\title{
SARS-CoV-2 Epidemics in Retirement and Nursing Homes in Italy: A New Preparedness Assessment Model after the First Epidemic Wave
}

\author{
Carmelo Gugliotta ${ }^{1, *++}$, Davide Gentili ${ }^{1,+}+\mathbb{D}$, Silvia Marras ${ }^{1}\left(\mathbb{D}\right.$, Marco Dettori ${ }^{1, *} \mathbb{\infty}$, Pietro Paolo Muglia ${ }^{1}$, \\ Maria Giuseppina Desole ${ }^{2}$, Marcello Acciaro ${ }^{3}$, Sabina Bellu ${ }^{4}$, Antonio Azara ${ }^{1,4}\left(\mathbb{C}\right.$ and Paolo Castiglia ${ }^{1,4}$ (D) \\ 1 Department of Medical, Surgical and Experimental Sciences, University of Sassari, 07100 Sassari, Italy; \\ d.gentili@studenti.uniss.it (D.G.); ma.silvia.87@gmail.com (S.M.); p.p.muglia@live.it (P.P.M.); \\ azara@uniss.it (A.A.); castigli@uniss.it (P.C.) \\ 2 ASSL Sassari, 07100 Sassari, Italy; mariagiuseppina.desole@atssardegna.it \\ 3 Regional Agency Emergency and Urgent Care Sardinia, AREUS, 07100 Sassari, Italy; \\ marcello.acciaro@areus.sardegna.it \\ 4 University Hospital of Sassari, 07100 Sassari, Italy; sabina.bellu@aousassari.it \\ * Correspondence: gugliotta.melo@gmail.com (C.G.); madettori@uniss.it (M.D.) \\ + These authors contributed equally to this work.
}

Citation: Gugliotta, C.; Gentili, D.; Marras, S.; Dettori, M.; Muglia, P.P.; Desole, M.G.; Acciaro, M.; Bellu, S.; Azara, A.; Castiglia, P. SARS-CoV-2 Epidemics in Retirement and Nursing Homes in Italy: A New Preparedness Assessment Model after the First Epidemic Wave. Int. J. Environ. Res. Public Health 2021, 18, 5712. https:// doi.org/10.3390/ijerph18115712

Received: 12 March 2021

Accepted: 24 May 2021

Published: 26 May 2021

Publisher's Note: MDPI stays neutral with regard to jurisdictional claims in published maps and institutional affiliations.

Copyright: (c) 2021 by the authors. Licensee MDPI, Basel, Switzerland. This article is an open access article distributed under the terms and conditions of the Creative Commons Attribution (CC BY) license (https:/ / creativecommons.org/licenses/by/ $4.0 /)$.

\begin{abstract}
The aim of the study is to evaluate the preparedness of retirement and nursing homes in the city of Sassari at the end of the first wave of the severe acute respiratory syndrome coronavirus 2 epidemic, first by investigating the risk perception of epidemic outbreaks by the facility managers and subsequently by carrying out a field assessment of these facilities. To perform the field assessment, a checklist developed by the CDC (Infection Prevention and Control Assessment Tool for Nursing Homes Preparing for COVID-19) and adapted to the Italian context was used. Fourteen facilities took part in the survey (87.5\%). The application of good practices for each survey area was expressed as a percentage with the following median values: restriction policies $(87.5 \%)$, staff training (53.8\%), resident training $(67.6 \%)$, availability of personal protective equipment $(41.7 \%)$, infection control practices $(73.5 \%)$ and communication $(80 \%)$. Among the facilities, considerable variability was observed in these evaluation fields: only the restriction policies and communication activities were applied uniformly. A discrepancy was found between perceived risk and real danger in the facilities, requiring targeted communication actions. At present, it is necessary to promote a new approach based on the prediction of critical events, thereby providing the means to effectively address them.
\end{abstract}

Keywords: COVID-19; preparedness; risk communication; nursing home; infection prevention and control

\section{Introduction}

Italy was the first European country to be severely affected by the coronavirus disease 19 (COVID-19) pandemic. According to data from the European Centre for Disease Prevention and Control (ECDC), Italian National Institute of Health (ISS) and the Italian National Institute of Statistics (ISTAT), by 20 March, Italy had reached the peak of COVID-19 cases during the first phase of the pandemic, surpassing that of China [1-3].

Pandemics affect a large proportion of the population and require a multisectoral response spanning months or even years. Preparedness for such an event is a continuous process of planning, exercising, revising and translating into action national and subnational response plans [4].

According to the United Nations Office for Humanitarian Affairs and the World Health Organization, the term 'preparedness' refers to the ability of governments, professional response organizations, communities and individuals to anticipate and respond effectively to the impact of likely, imminent or current hazards, events or conditions. An adequate 
level of preparedness can make a major difference in saving lives and reducing suffering. Moreover, it ensures that scarce resources are directed where they will have the greatest impact $[5,6]$.

Being properly prepared for a major epidemic and pandemic event requires a combination of political will, financial investment, and public health expertise. To further improve the prevention, identification, and response to infectious disease outbreaks, it is essential to identify the most important challenges to address based on existing knowledge and previous experience of epidemic emergencies $[7,8]$.

In the last two decades, the world has witnessed numerous major epidemics or pandemics, five of which (2009 H1N1 pandemic, 2014 Ebola virus epidemic, 2014 poliovirus epidemic, 2016 Zika virus epidemic, 2018 Ebola virus epidemic) have been declared "Health Emergencies of International Interest" by the World Health Organization (WHO). These events should remind us to remain extremely vigilant, taking advantage of interpandemic periods to improve preparedness and gain knowledge from past experiences. Moreover, a better preparedness should be sought as a priority, especially for the protection of vulnerable people [9].

During the emergency, numerous residential facilities for the elderly in Italy have been the loci of major outbreaks $[10,11]$. Furthermore, these structures also had a lower response capacity than hospital facilities to control the disease. The biggest issues were the lower provision of personal protective equipment, the lack of specific preparedness, and a logistical-structural organization that often failed to set up adequate spaces to isolate sick residents $[12,13]$.

Data from a survey by the Italian National Institute of Health (ISS) shows that in the first half of 2020, in Italy, more than $7 \%$ of the total number of deaths in residential facilities for the elderly involved residents infected with SARS-CoV-2 and that over $30 \%$ of the death toll had COVID-like symptoms [10]. During the same period, Sardinia showed a low risk for COVID-19 cases and COVID-19 mortality [14] but the number of cases among residents in long-term care facilities accounted for more than $40 \%$ of the total registered COVID-19 cases [15].

In addition to advanced age, residents in these long-term care facilities have a further risk of encountering unfavorable outcomes, due to the presence of comorbidities and chronic diseases. Moreover, these conditions often make it difficult to recognize the typical symptoms of COVID-19 [16,17].

For these reasons, retirement and nursing homes are a reference setting for public health initiatives aimed at supporting the best practices of infection prevention and control and reducing the likelihood of outbreaks in these facilities.

A guiding principle for any public health initiative in the first place is to set up an adequate communication strategy. During a risk communication process, the first task is to ascertain the real risk within a target population. The hazards are not always commensurate to the actual risks: outrage, an emotional factor that influences risk perception, affects people's perception of the real danger of an event [18-24].

In the different risk communication scenarios, a targeted approach is required, and effective risk communication is essential to limit morbidity and mortality caused by communicable diseases, in addition to enabling the appropriate management of available resources $[25,26]$. The ability to provide timely and effective responses at an early stage, despite the scientific uncertainties and different resource capacities, is a key element to dealing with a public health crisis. Preparedness assessment should be carried out at all levels of a healthcare organization, including in residential facilities responsible for assisting fragile people such as nursing homes and retirement homes.

Finally, standardized tools for assessing preparedness in residential facilities for the elderly at national and subnational levels are lacking, and infection prevention and control practices are not routinely monitored.

Based on these premises, the aim of this study is primarily to evaluate perceived risk by all residential facilities for the elderly in the city of Sassari following the first wave of 
the SARS-Cov-2 epidemic, and subsequently, through a field inspection of each facility, to identify critical control points in order to avoid new outbreaks and provide an intervention model that could be used for a large-scale preparedness assessment of these facilities.

\section{Materials and Methods}

The present study did not require ethical approval for its observational design according to Italian law (Gazzetta Ufficiale no. 76 dated 31 March 2008).

\subsection{Study Setting}

Sardinia was one of the most affected areas of the country during the first epidemic wave considering its low population density. Even though age-adjusted attack rates in the region were classified as low [27] and the COVID-19 standardized mortality rate was lower than the Italian one [14], there was an overall increase in mortality of $13.7 \%$ in March 2020 compared with the average value in the same reference period for the years 2015 to 2019 [28]. Moreover, due to its insularity, Sardinia has particular genetic features that make its population suitable for epidemiological studies [29-31].

The island is located in the Mediterranean Sea, over an area of 24,100 $\mathrm{Km}^{2}$. The region is divided into four provinces (Nuoro, Oristano, Sassari, Sud Sardegna) and a metropolitan city (Metropolitan City of Cagliari). Sardinia has the oldest population in Italy: according to data provided by the National Statistical Institute, as of 1 January 2020 (Table 1), the average age of residents was 47.3 years (the Italian average age was 45.7 years). The province of Sassari has the lowest old-age index (202.7) in the region, but this value is higher than the index detected at the national level (178.4) [32].

Table 1. Istat demographic indicators 2020.

\begin{tabular}{lccccccc}
\hline & Italy & Sardinia & Sassari & Nuoro & Cagliari & Oristano & $\begin{array}{c}\text { Sud } \\
\text { Sardegna }\end{array}$ \\
\hline Old-age index (\%) & 178.4 & 221.6 & 202.7 & 216.7 & 204.8 & 272.8 & 255.4 \\
\hline $\begin{array}{c}\text { Average age of the } \\
\text { population }\end{array}$ & 45.7 & 47.3 & 46.6 & 47.1 & 46.7 & 48.8 & 48.3 \\
\hline
\end{tabular}

The first case of SARS-CoV-2 infection in the island was reported on 2 March in the metropolitan area of Cagliari. In the following days, there was a moderate increase in the number of cases. On 14 March, the first hospital outbreak occurred in the cardiology ward of the University Hospital of Sassari. As of that date, 77 cases had been identified on the island, 35 of which were reported in the province of Sassari, making it the most affected area in the region $[33,34]$.

The district of Sassari was the most affected area throughout the first wave of the COVID-19 epidemic. As of 31 May 2020, 1356 cases were identified in the region, $64.2 \%$ (870) of which were in Sassari (Figure 1), and more than $40 \%$ among residents in long-term care facilities [15]. 


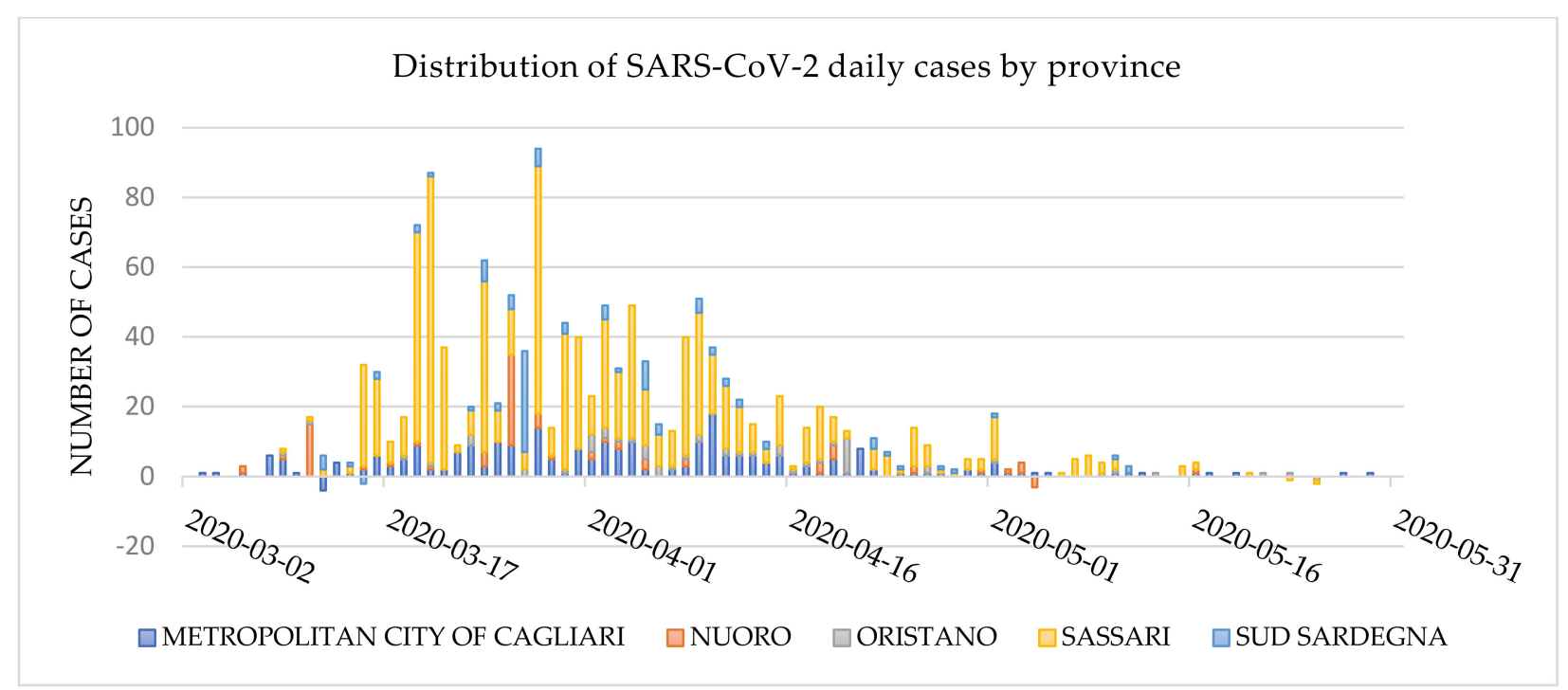

Figure 1. Daily distribution of SARS-CoV-2 cases by Sardinian district as of 31 May 2020 (data source: Civil Protection Database).

\subsection{Questionnaire Investigation}

In June 2020, a survey was carried out in the city of Sassari to identify all the residential facilities that provided assistance to the elderly and infirm in the city. The investigation identified 16 residential facilities, two of which were nursing homes. Information was gathered regarding the epidemiological situation inside these facilities and the spread of SARS-CoV-2 in the March to May 2020 timeframe.

A letter describing the objectives of the project, the stakeholders involved, and the survey methods was sent to these facilities. Commitment to the project was requested through the completion of a digital survey by the head of the facility (Supplementary Materials, Table S1), using the EUSurvey platform (the European Commission's official survey management tool). To refine and validate the survey, a two-stage empirical validation study was conducted. This consisted of a pretest with a panel of domain experts, followed by a discussion on the questionnaire with the manager and the healthcare staff of a facility for the elderly not included in our project.

The purpose of this preliminary assessment was mainly exploratory and involved gathering information about the organization and the management of the facilities during the first phase of the COVID-19 emergency. This step also marked the first contact between the group responsible for the investigation and the residential structures involved in the project.

\subsection{ICAR Tool}

The Infection Control Assessment and Response Tool (ICAR), developed by the US Center for Disease Control and Prevention, was used for the field investigation to assess a healthcare facility's infection prevention and control (IPC) practices and to guide quality improvement activities (by identifying and addressing gaps) in a standardized manner [35].

The ICAR checklist was adapted to the Italian context according to regulations provided by the Ministry of Health and the National Institute of Health (ISS) on the management of residential facilities for the elderly [36]. In particular, facility access restrictions were brought into line with the national law, cloth face coverings were not permitted in place of facemasks, the minimum distance between residents was set at $1 \mathrm{~m}$ (wherever possible, $1.8 \mathrm{~m}$ ) and facilities' chains of communication for suspected or confirmed cases of COVID-19 were adjusted to the regional health organization (family doctors of the residents, as well as health department, must be promptly informed). 
The items assessed by the ICAR checklist included key strategies for keeping COVID19 out of the facility, identifying infections as early as possible, preventing the spread of infections within the facility, assessing, and optimizing personal protective equipment (PPE) supplies and identifying and managing severe illness in residents with COVID-19. These items are grouped into six areas for monitoring: restrictions on visitors and nonessential personnel; education, monitoring, and screening of healthcare personnel (HCP); education, monitoring, screening and cohorting of residents; availability of PPE and other supplies; infection prevention and control (IPC) practices; and communication. A detailed explanation of each assessment area is featured on the original CDC checklist [35].

\subsection{Field Investigation}

The field investigation provided an opportunity for dialogue and information sharing, emphasizing that it was not a regulatory inspection and was designed to ensure the facility was prepared to quickly identify and prevent the spread of COVID-19. A team of four medical doctors, residents in Hygiene and Preventive Medicine from the University of Sassari and a nurse specialized in infection control risk assessment were set up for the task. The team underwent a week of training, with the aim of minimizing any variability during the field investigation. Every item of the checklist was tested, identifying shared methods of detection for each element of the ICAR. Each member of the investigation team was then assigned a specific section of the ICAR checklist to study and discuss.

The field investigation was carried out from mid-June to the end of July 2020 with a single visit for each facility and after having received a reply to the introductory questionnaire. Interviews were carried out with the facilities' managers and COVID-19 representatives, staff on duty at the time of the survey and with the staff responsible for cleaning. In each facility, the visit was carried out with a direct observation of the assistance areas, the isolation/quarantine rooms, and residents' shared areas, including the dining area and the spaces reserved for staff. Routine activities of health-care workers were also observed, especially those concerning infection prevention and control practices (IPC). In addition to the information collected, the facility manager and/or the person in charge of COVID-19 procedures were asked if a written plan had been drawn up specifically for the Sars-Cov-2 emergency and if the competent health authorities had transmitted information on the epidemic prior to the local emergency.

\subsection{Statistical Analysis}

At the end of each field investigation, the completeness of the information collected and the consistency of data between each team member were verified in a briefing. Subsequently, data were entered into a Microsoft Excel worksheet by two members of the team and analyzed using the IBM SPSS Version 20 statistical software. The Mann-Whitney U test was used to compare the distributions of the ICAR checklist scores between facility groups with and without previous SARS-CoV-2 cases.

For every facility in each macro-area of the ICAR checklist, a score was calculated from the ratio between the sum of the individual items in that area (a value of 1 point was attributed if the element was present) and the number of items in the section, reported as a percentage. In the exact same way, a global score for each facility was obtained, taking into consideration all six areas of the ICAR checklist, also reported as a percentage.

In addition, an evaluation of risk perception versus actual hazard in the facilities was made so as to formulate subsequent risk communication strategies. One point was given for each item fulfilled in IPC practices, quarantine/isolation and training areas (Table 2), both in the introductory questionnaire and the ICAR checklist used for the field assessment. 
Table 2. Indicators of risk perception versus facilities hazard assessment (each item was given one point if performed).

\begin{tabular}{l}
\multicolumn{1}{c}{ Facilities' Perception } \\
\hline \multicolumn{1}{c}{ (Items Extracted from Introductory Questionnaire) } \\
\hline IPC Pract \\
Body temperature is monitored for all staff before entering the facility \\
$\begin{array}{l}\text { At the entrance of the facility, alcohol-based hand rub (ABHR) is } \\
\text { available for everyone }\end{array}$
\end{tabular}

Anyone entering the facility wears a surgical mask for the entire length of stay

Assessment of Facilities

Assessment of Facilities
(Items Extracted from the ICAR Checklist)

Body temperature is measured daily for all the residents of the facility

A facility staff member has been identified to verify the correct use of PPE by health workers and proper hand hygiene

The ABHR is readily available to all healthcare staff during patient care activities

All HCP (including everyone in the facility staff) are screened at the beginning of their shift for fever and symptoms of COVID-19

Potential visitors are screened prior to entry for fever or symptoms of COVID-19. Those with symptoms are not permitted to enter the facility

Visitors that are permitted inside must wear a cloth face covering while in the building and restrict their visit to the resident's room or other location designated by the facility. They are also reminded to frequently perform hand hygiene

The facility assesses residents for fever and symptoms of COVID-19 upon admission and at least daily throughout their stay in the facility

The facility monitors HCP adherence to recommended IPC practices

PPE is available in resident care areas including outside resident rooms

\section{Quarantine/Isolation}

Newly admitted residents are housed in a dedicated room and avoid contact with other people during the observation period (14 days)

Newly admitted residents are swabbed before entering the facility and at the end of the observation period (14 days)

There is a procedure for rapid isolation of people with a new confirmed/suspected case of COVID-19 and the case is reported to the referring physician

Transfer of a COVID-19 confirmed/suspected case to another facility is expected if adequate isolation of the subject cannot be arranged

The facility has a plan for managing new admissions and readmissions whose COVID-19 status is unknown

The facility has dedicated a team of primary HCP staff to work only in this area of the facility

The facility has a plan for how to deal with residents in the facility who develop COVID-19

The facility has dedicated a space in which to care for residents with confirmed COVID-19.

A dedicated area of the facility has been identified and could be used in case of a high number of COVID-19 cases (cohort isolation)

Availability of beds in isolation facilities assessed at time of survey Training

Facility staff (including non-employees) are expressly informed not to attend work with fever, myalgia, asthenia or respiratory/gastrointestinal symptoms

The facility staff has been informed to avoid close contact between colleagues, except for any resident care activity if necessary

The facility has provided education and refresher training to HCP (including consultant personnel) about the following: COVID-19

The facility has provided education and refresher training to HCP (including consultant personnel) about the following: sick leave policies and the importance of not reporting to or remaining at work when sick

Caregivers are trained in the procedure to be taken when a new resident enters the facility (from hospital/household)

The facility has provided education and refresher training to HCP (including consultant personnel) about the following: new policies for source control while in the facility

Facility staff are trained on the procedure to be adopted in case of a new confirmed/suspected COVID-19 host

The facility has provided staff with education on how to use a facemask or respirator if more than source control is required

Specific training was carried out

All HCP are reminded to practice social distancing when in break rooms and common areas

If HCP are ill, they are instructed to keep their cloth face covering or facemask on and leave the facility. HCP with suspected or confirmed COVID-19 should notify their supervisor at any facility where they work

More than $50 \%$ of the facility staff has attended the specific training activities

The perception of safety by each facility was considered as a proxy for assessing the perceived risk (perceived safety $=1$ perceived risk). Likewise, the score of the external evaluation depicts the complementary value to the real danger assessed. Our graphical representation of these variables therefore shows an inversion in the $\mathrm{XY}$ axis compared to the classic outrage-hazard Sandman model.

Three pairs of indicators were devised to compare the risk perceived by the facilities (evaluated by items extracted from the introductory questionnaire) with the danger assessed by the team during the field investigation (evaluated by items extracted from the 
ICAR checklist) in each area. Each indicator is the percentage of items fulfilled for each of the three areas of the questionnaire and the ICAR checklist.

\section{Results}

\subsection{Introductory Questionnaire Results}

Fourteen of the 16 facilities (87.5\%) identified within the city of Sassari participated in the project. Two of these are nursing homes (14.3\%), while the remaining are retirement homes $(85.7 \%)$. The sample comprises structures with heterogeneous structural characteristics. There are both small (a limited number of beds and residential rooms) and large structures. The total number of beds available in the 14 facilities is 790 units (median 40; range of values 15 to 136 ).

At the beginning of the survey, $88.8 \%$ of the beds were occupied by 617 residents. Out of the total of 591 rooms in these facilities (median 24.5; range 12 to 117), 41.6\% (246) are single rooms (median 9; range 0 to 64 ). According to data reported by the facilities, 45 beds had been earmarked for quarantining new inhabitants $(5.7 \%$ of the total number of beds) and 39 for isolating possible, probable, or confirmed cases $(4.9 \%)$. At the time of data collection, there were 47 nurses $(9.4 \%)$ and 224 social and health workers (44.7\%) out of the total employees in the 14 facilities.

Prior to this study, two facilities had had a SARS-CoV-2 outbreak with a total of 251 cases among residents and healthcare workers. The period prevalence of infection in the two facilities was $58.8 \%$ (164 positives out of 279 ) among residents and $30.2 \%$ among the healthcare workers (87 positives out of 288), with a significant difference between the groups $(p<0.05)$. Demographic information, lethality by age and gender, and comorbidity of SARS-CoV-2 cases are reported in Table 3.

Table 3. Characteristics of SARS-CoV-2 cases among facilities with outbreaks during the first pandemic phase.

\begin{tabular}{|c|c|c|c|c|c|c|}
\hline Variables & \multicolumn{2}{|c|}{ Residents } & \multicolumn{2}{|c|}{ Healthcare Workers } & \multicolumn{2}{|c|}{ Total } \\
\hline Age (Mean, SD) & \multicolumn{2}{|c|}{$81.0( \pm 11.0)$} & \multicolumn{2}{|c|}{$47.0( \pm 10.0)$} & \multicolumn{2}{|c|}{$69.4( \pm 19.5)$} \\
\hline Gender & $n$ & $\%$ & $n$ & $\%$ & $n$ & $\%$ \\
\hline Female & 101 & 61.6 & 66 & 75.9 & 167 & 66.5 \\
\hline Male & 63 & 38.4 & 21 & 24.1 & 84 & 43.5 \\
\hline \multicolumn{7}{|l|}{ Lethality by group } \\
\hline Female & $19 / 101$ & 18.8 & $0 / 66$ & 0 & $19 / 167$ & 11.4 \\
\hline Male & $17 / 63$ & 27.0 & $0 / 21$ & 0 & $17 / 84$ & 20.2 \\
\hline$>90$ years & $9 / 26$ & 34.6 & 0 & 0 & $9 / 26$ & 34.6 \\
\hline 80 to 89 years & $21 / 80$ & 26.3 & 0 & 0 & $21 / 80$ & 26.3 \\
\hline 70 to 79 years & $4 / 28$ & 14.3 & 0 & 0 & $4 / 28$ & 14.3 \\
\hline 60 to 69 years & $2 / 12$ & 16.7 & $0 / 10$ & 0 & $2 / 22$ & 9.1 \\
\hline$<60$ years & $0 / 18$ & 0 & $0 / 77$ & 0 & $0 / 95$ & 0 \\
\hline Total & $36 / 164$ & 22.0 & 0 & 0 & $36 / 251$ & 14.3 \\
\hline \multicolumn{7}{|l|}{ Comorbidities } \\
\hline No & 5 & 3.1 & 77 & 88.5 & 82 & 32.7 \\
\hline Unknown & 91 & 55.4 & 3 & 3.4 & 94 & 37.4 \\
\hline Yes & 68 & 41.5 & 7 & 8.1 & 75 & 29.9 \\
\hline \multicolumn{7}{|l|}{ Distribution of comorbidities } \\
\hline Cardiovascular diseases & 34 & 50.0 & 0 & 0 & 34 & 45.3 \\
\hline Chronic Respiratory diseases & 18 & 26.5 & 3 & 42.9 & 21 & 28.0 \\
\hline Metabolic Diseases & 12 & 17.7 & 0 & 0 & 12 & 16.0 \\
\hline
\end{tabular}


Table 3. Cont.

\begin{tabular}{|c|c|c|c|c|c|c|}
\hline \multirow{2}{*}{$\begin{array}{c}\text { Variables } \\
\text { Kidney diseases }\end{array}$} & \multicolumn{2}{|c|}{ Residents } & \multicolumn{2}{|c|}{ Healthcare Workers } & \multicolumn{2}{|c|}{ Total } \\
\hline & 10 & 14.7 & 0 & 0 & 10 & 13.3 \\
\hline Cancer & 8 & 11.8 & 0 & 0 & 8 & 10.7 \\
\hline Diabetes Mellitus & 7 & 10.3 & 0 & 0 & 7 & 9.3 \\
\hline Chronic neurological diseases & 5 & 7.4 & 0 & 0 & 5 & 6.7 \\
\hline Obesity (BMI 30 to 40) & 3 & 4.4 & 0 & 0 & 3 & 4.0 \\
\hline HIV & 2 & 2.9 & 0 & 0 & 2 & 2.7 \\
\hline Other Conditions & 51 & 75.0 & 5 & 71.4 & 56 & 74.7 \\
\hline
\end{tabular}

The mean number of comorbidities found is $2.5 \pm 1.6$. Similar data has already been reported in previous experiences, aimed at examining the health conditions of subjects who had died of COVID-19 [15]. By evaluating the comorbidity classified as "other conditions", a misclassification was detected which could weigh on an underestimation of the other classes of comorbidity (especially for chronic neurological diseases).

At the time of the survey, no facility had any cases of SARS-CoV-2 infection among residents and staff.

The facilities were able to report adherence to infection prevention and control practices together with procedures that had been implemented since the beginning of the state of emergency by the pre-audit questionnaire. For some of these practices, the facilities reported $100 \%$ adhesion (ABHR dispenser available at the entrance of the facility, instructing facility staff to stay at home if sick, restricting visitation in the facility, use of surgical masks by visitors, screening of staff at the entrance of the facility by measuring body temperature, facility staff informed on the procedures for admitting a new resident; facility staff informed about social distancing, facility staff informed on procedures to adopt for a possible or probable COVID-19 case, periodic sanitation of workers' premises, presence of a supervisor for monitoring consumption and purchase of PPE; ABHR available to all facility staff, rapid isolation procedures and reporting of possible, probable or confirmed cases).

The lowest adhesions were reported in the provision of an area for cohort isolation of patients and for putting in place a procedure for transferring cases whenever effective isolation could not be provided (64.3\% of the facilities). Specific training for COVID-19 was reported in 10 facilities (75.4\%) with involvement of more than $75 \%$ of the staff in only eight of these structures (Table 4).

Table 4. Results of the introductory questionnaire $(N=14)$.

\begin{tabular}{lcc}
\hline General Structure & $n$ & $(\%)$ \\
\hline Accomodation facility & & \\
\hline Nursing home & 2 & $(14.3 \%)$ \\
\hline Retirement home & 12 & $(85.7 \%)$ \\
\hline Information on the facility, residents and staff & Median & $($ Range $)$ \\
\hline Total number of beds & 40 & $(15-163)$ \\
\hline Total number of residential rooms & 24.5 & $(12-117)$ \\
\hline Total number of single residential rooms & 9 & $(0-64)$ \\
\hline Current number of resident guests & 35.5 & $(10-104)$ \\
\hline Number of beds predisposed for COVID-19 isolation & 2 & $(0-9)$ \\
\hline Number of COVID-19 cases are currently confirmed among residents & 0 & $(0-0)$ \\
\hline Number of beds set up for quarantine period and contact monitoring & 1 & $(0-13)$ \\
\hline
\end{tabular}


Table 4. Cont.

\begin{tabular}{|c|c|c|}
\hline $\begin{array}{l}\text { Number of subjects who provide activities in the structure } \\
\text { (employees and non-employees.) }\end{array}$ & 17 & $(11-160)$ \\
\hline Number of Nurses in the structure & 2 & $(0-14)$ \\
\hline Number of social and health workers employed in the structure & 10 & $(1-70)$ \\
\hline Number of COVID-19 cases currently confirmed among facility staff & 0 & $(0-0)$ \\
\hline Procedures performed by facilities & $n$ & $(\%)$ \\
\hline Fourteen-day observation period for new residents & 12 & $(85.7 \%)$ \\
\hline $\begin{array}{l}\text { Nasopharyngeal swab performed at the beginning and at the end of } \\
\text { the observation period }\end{array}$ & 12 & $(85.7 \%)$ \\
\hline Facility staff advised not to attend work if symptomatic & 14 & $(100 \%)$ \\
\hline Body temperature assessment before entering the facility & 14 & $(100 \%)$ \\
\hline All entrances of the facilities are provided with ABHR & 14 & $(100 \%)$ \\
\hline Use of surgical face mask for entire duration of stay (visitors) & 14 & $(100 \%)$ \\
\hline $\begin{array}{l}\text { Instructions provided to facility staff on limiting contact if not } \\
\text { needed for patient care }\end{array}$ & 14 & $(100 \%)$ \\
\hline Restrictions on visits by family members & 14 & $(100 \%)$ \\
\hline Daily body temperature measurement for all residents in the facility & 13 & $(92.9 \%)$ \\
\hline Staff informed on facility admission procedures for new residents & 14 & $(100 \%)$ \\
\hline $\begin{array}{l}\text { Expected rapid isolation procedure of COVID-19 } \\
\text { suspected/confirmed cases and reporting to the referring doctor }\end{array}$ & 14 & $(100 \%)$ \\
\hline $\begin{array}{l}\text { Expected procedure for transferring COVID-19 suspected/confirmed } \\
\text { cases in the impossibility of isolation }\end{array}$ & 9 & $(64.3 \%)$ \\
\hline $\begin{array}{l}\text { Information provided to facility staff on the procedures to perform in } \\
\text { the event of a suspected/confirmed case }\end{array}$ & 14 & $(100 \%)$ \\
\hline $\begin{array}{l}\text { Dedicated space provided within the facilities for cohort isolation of } \\
\text { COVID-19 cases }\end{array}$ & 9 & $(64.3 \%)$ \\
\hline $\begin{array}{l}\text { Member of facility staff identified to verify the correct use of PPE by } \\
\text { health workers and proper hand hygiene }\end{array}$ & 12 & $(85.7 \%)$ \\
\hline Alcohol-based hand rub readily available to all facility staff & 14 & $(100 \%)$ \\
\hline Periodic sanitation of facility staff rooms & 14 & $(100 \%)$ \\
\hline $\begin{array}{l}\text { Facility has a person in charge for the control of consumption, } \\
\text { purchases and stocks of PPE }\end{array}$ & 14 & $(100 \%)$ \\
\hline \multicolumn{3}{|l|}{ The cleaning staff is: } \\
\hline Part of the facility workforce & 12 & $(85.8 \%)$ \\
\hline External staff & 1 & $(7.1 \%)$ \\
\hline Partly in the workforce and partly external to the facility & 1 & $(7.1 \%)$ \\
\hline \multicolumn{3}{|l|}{ Specific COVID-19 training carried out for staff (HCA, Nurses, etc): } \\
\hline No & 4 & $(28.6 \%)$ \\
\hline Yes, theoretical & 5 & $(35.7 \%)$ \\
\hline Yes, theoretical-practical & 5 & $(35.7 \%)$ \\
\hline \multicolumn{3}{|l|}{ Percentage of the staff who completed dedicated COVID-19 training. } \\
\hline Less than $25 \%$ & 0 & $(0 \%)$ \\
\hline 25 to $50 \%$ & 1 & $(10 \%)$ \\
\hline 51 to $75 \%$ & 1 & $(10 \%)$ \\
\hline Over $75 \%$ & 8 & $(80 \%)$ \\
\hline
\end{tabular}




\subsection{Field Assessment Results}

The 66 items assessed by the ICAR checklist were divided into six specific macro-areas (Table 5).

Table 5. Application of checklist procedures in residential facilities for elderly people in the city of Sassari $(N=14)$.

\begin{tabular}{|c|c|c|}
\hline 1. Restrictions on visitors and non-essential personnel & $n$ & $(\%)$ \\
\hline Limitation of visits & 14 & $(100 \%)$ \\
\hline Exceptions assessed individually & 7 & $(50 \%)$ \\
\hline Visitor screening & 12 & $(86 \%)$ \\
\hline Visitor behavioral restrictions & 12 & $(86 \%)$ \\
\hline Suspension of non-essential services & 14 & $(100 \%)$ \\
\hline Communication of facility's lockdown to family members & 12 & $(86 \%)$ \\
\hline Alternative methods to the visit & 14 & $(100 \%)$ \\
\hline Presence of information boards at entrances & 3 & $(21 \%)$ \\
\hline $\begin{array}{l}\text { 2. Education, Monitoring, and Screening of Healthcare Personnel } \\
\text { (HCP) }\end{array}$ & $n$ & $(\%)$ \\
\hline Staff education: COVID-19 & 6 & $(43 \%)$ \\
\hline Staff education: Sick leave & 14 & $(100 \%)$ \\
\hline Staff education: New infection control policies & 10 & $(71 \%)$ \\
\hline Monitoring: Hand Hygiene Audit & 2 & $(14 \%)$ \\
\hline Monitoring: PPE Selection and Use Audit & 2 & $(14 \%)$ \\
\hline Monitoring: Cleanliness and Disinfection Audit & 2 & $(14 \%)$ \\
\hline Staffing Needs and Shortage Plan & 5 & $(36 \%)$ \\
\hline Universal use of face masks & 12 & $(86 \%)$ \\
\hline Instruction given to facility staff on different types of masks & 6 & $(43 \%)$ \\
\hline Instruction given to facility staff on social distancing & 11 & $(79 \%)$ \\
\hline Staff screening at the beginning of the work shift & 11 & $(79 \%)$ \\
\hline $\begin{array}{l}\text { Information on how to behave in case of symptoms while working in } \\
\text { the facility }\end{array}$ & 12 & $(86 \%)$ \\
\hline Staff symptoms log & 6 & $(43 \%)$ \\
\hline 3. Education, Monitoring, and Screening, and Cohorting of Residents & $n$ & $(\%)$ \\
\hline Information: COVID-19 & 14 & $(100 \%)$ \\
\hline Information: informing facility staff of the onset of symptoms & 13 & $(93 \%)$ \\
\hline Information: protective actions to be implemented & 14 & $(100 \%)$ \\
\hline Information: protective actions implemented by the facility & 14 & $(100 \%)$ \\
\hline Daily monitoring of symptoms & 10 & $(71 \%)$ \\
\hline Application of precautions to suspected COVID-19 cases & 13 & $(93 \%)$ \\
\hline Symptomatic resident $\log$ & 10 & $(71 \%)$ \\
\hline Interruption of community activities & 5 & $(36 \%)$ \\
\hline Interruption of communal catering & 4 & $(29 \%)$ \\
\hline Additional actions in emergency: movements restriction & 4 & $(29 \%)$ \\
\hline $\begin{array}{l}\text { Additional actions in emergency: movements not restricted but } \\
\text { precautions to be taken }\end{array}$ & 6 & $(43 \%)$ \\
\hline
\end{tabular}


Table 5. Cont.

\begin{tabular}{|c|c|c|}
\hline Monitoring sick residents three times a day & 12 & $(86 \%)$ \\
\hline Dedicated COVID-19 area & 10 & $(71 \%)$ \\
\hline Dedicated COVID-19 team & 2 & $(14 \%)$ \\
\hline COVID-19 patient management plan & 9 & $(64 \%)$ \\
\hline New admission/readmission management plan & 8 & $(57 \%)$ \\
\hline $\begin{array}{l}\text { Use of recommended PPE in COVID-19 areas or facility-wide if high } \\
\text { number of cases }\end{array}$ & 12 & $(86 \%)$ \\
\hline $\begin{array}{l}\text { 4. Availability of Personal Protective (PPE) Equipment and other } \\
\text { Supplies }\end{array}$ & $n$ & $(\%)$ \\
\hline PPE supply assessment & 10 & $(71 \%)$ \\
\hline Involvement of the Prevention Department for PPE shortages & 5 & $(36 \%)$ \\
\hline PPE supply optimisation measures & 7 & $(50 \%)$ \\
\hline PPE near to the patient care areas & 0 & $(0 \%)$ \\
\hline Availability of virucidal disinfectants & 14 & $(100 \%)$ \\
\hline Wipes/bins available for respiratory hygiene in shared spaces & 5 & $(36 \%)$ \\
\hline 5. Infection Prevention and Control Practices & $n$ & $(\%)$ \\
\hline Hand hygiene: before resident contact, even if gloves will be worn & 12 & $(86 \%)$ \\
\hline Hand hygiene: after contact with the resident & 9 & $(64 \%)$ \\
\hline $\begin{array}{l}\text { Hand hygiene: after contact with blood, body fluids, or contaminated } \\
\text { surfaces or equipment }\end{array}$ & 10 & $(71 \%)$ \\
\hline Hand hygiene: before performing an aseptic task & 6 & $(43 \%)$ \\
\hline Hand hygiene: after removing PPE & 11 & $(79 \%)$ \\
\hline Facility favors use of ABHR & 4 & $(29 \%)$ \\
\hline PPE used in suspected/confirmed cases: gloves & 14 & $(100 \%)$ \\
\hline PPE used in suspected/confirmed cases: coveralls & 13 & $(93 \%)$ \\
\hline PPE used in suspected/confirmed cases: FFP2/FFP3 & 12 & $(86 \%)$ \\
\hline PPE used for suspected/confirmed cases: eye protection & 12 & $(86 \%)$ \\
\hline Proper PPE removal and subsequent hand hygiene & 11 & $(79 \%)$ \\
\hline Hand hygiene supply available in care areas & 7 & $(50 \%)$ \\
\hline Monitoring: hand hygiene adherence and correct use of PPE & 2 & $(14 \%)$ \\
\hline Disinfection of shared patient care equipment & 11 & $(79 \%)$ \\
\hline Suitability of disinfectants for environmental cleaning & 14 & $(100 \%)$ \\
\hline Knowledge of contact times of disinfectants & 4 & $(29 \%)$ \\
\hline Use of disinfectant according to label instructions & 13 & $(93 \%)$ \\
\hline 6. Communication & $n$ & $(\%)$ \\
\hline Public Health Communication: single case suspected or confirmed & 13 & $(93 \%)$ \\
\hline Public Health Communication: worsening of respiratory symptoms & 14 & $(100 \%)$ \\
\hline $\begin{array}{l}\text { Public Health Communication: multiple cases of respiratory } \\
\text { symptoms }\end{array}$ & 12 & $(86 \%)$ \\
\hline $\begin{array}{l}\text { Procedures for informing family members and staff about } \\
\text { suspected/confirmed cases }\end{array}$ & 13 & $(93 \%)$ \\
\hline $\begin{array}{l}\text { Procedures for informing about suspected/confirmed cases during } \\
\text { intake from external services. }\end{array}$ & 9 & $(64 \%)$ \\
\hline
\end{tabular}




\subsubsection{Visit Restrictions and Non-Essential Personnel Restrictions}

All facilities (100\%) had limited visitors' access; they had suspended non-essential services and simultaneously activated alternative methods to visiting (operator-assisted video call was guaranteed in all facilities). In half of the residences, under special circumstances, visitors could access the facilities for exceptional assistance requirements (compassionate assistance and end of life). These exceptions, where provided, could only be approved by the manager of the structure. Communications regarding the new visitation policies of the facilities were sent by 12 residences $(86 \%)$ to all the residents' families by e-mail or by telephone. Twelve residences were equipped to screen visitors by measuring body temperature at the entrance of the facility and provided behavioral constraints during the visit (movement inside the facility limited to the resident's room or to a designated location, hand hygiene at the entrance and the obligation to wear a surgical mask for the entire duration of the visit). Only at the entrances of three structures (21\%) were there notices prohibiting access to visitors.

\subsubsection{Education, Monitoring, and Screening of Healthcare Personnel (HCP)}

This area aims to assess the activities that reduce the likelihood of healthcare staff acting as disease vectors within the facility. Only six structures (43\%) provided specific training on COVID-19, while information regarding new infection control policies was given in $71 \%$ of the structures and information about sick leave was provided for every facility. Internal audit activities concerning the adherence of facility staff to hand hygiene, the correct use of PPE and cleaning practices were carried out in $14 \%$ of the facilities. Moreover, the assessment of staff availability and an established recruitment method in the event of under-staffing was carried out only in five structures (36\%). The universal use of face masks by the facility staff was implemented in 12 residences for the elderly, but adequate information on the different types of face masks to be used during care assistance was given only by six facilities. Nearly $80 \%$ of the facilities screen staff by checking body temperature and COVID-19 symptoms at the beginning of the work shift. With the same frequency, social distancing between the facility staff is reiterated unless necessary for patient care.

There seems to be a clear direction to remove from the workplace staff who manifest symptoms of COVID-19 during daily activities or at the time of screening for body temperature and symptoms $(86 \%)$ while in a smaller number of facilities $(43 \%)$ any staff found to be symptomatic were documented.

\subsubsection{Education, Monitoring, and Screening, and Cohorting of Residents}

As in the previous section, the practices that reduce the likelihood of residents acting as infection vectors were identified. All the facilities made efforts to educate the residents to some extent about the disease, the symptoms, the actions that guests could take to protect themselves from infection and the actions that the staff was taking to protect them. However, the transmission of information to residents appears to be limited by the ability of the residents to manage the concepts provided by the facility staff.

Only 10 out of 14 structures had started a daily screening of residents for body temperature but almost all were aware of the need to adopt appropriate precautions to the residents even in the occasional finding of symptoms. In 10 facilities $(71 \%)$, there was a register of symptomatic residents or an annotation was made in the clinical diary. Internal limitations on the movement of residents were poorly applied and shared catering was active in most of the facilities, also due to the absence of active cases at the time of the survey.

Ten structures $(71 \%)$ had a dedicated area of the building for COVID-19 cases. Only two facilities (14\%) had planned to dedicate specific personnel to COVID-19 areas. A plan for the management of patients who develop COVID-19 was available in nine facilities while only eight structures had provided a plan for incoming residents with an unknown COVID-19 status. 


\subsubsection{Availability of Personal Protective (PPE) Equipment and other Supplies}

The main objective was to verify that an assessment had been carried out on the stocks of PPE available and that these stocks were sufficient to deal with a shortage situation on the market, as had occurred in an initial phase of the emergency. Adequate assessment had been performed in only 10 facilities (71\%). For any shortage of PPE, the involvement of the Prevention Department or the Health District was considered only in $36 \%$ of cases.

Half of the facilities had adopted procedures to optimize the use of PPE (priority access to health care personnel, based on patient care procedures, extended use of the devices). None of the investigated structures had an available kit of personal protective equipment near the assistance area or near the residents' rooms (it was mainly available in the staff changing areas or given to the staff by the person in charge for PPE management where present). All the facilities had acquired hospital-grade disinfectants with virucidal action on SARS-CoV-2 for the disinfection of surfaces, environments, and equipment. Only $36 \%$ of the facilities had made disposable wipes and easily accessible bins available in the common areas, promoting good respiratory hygiene practices.

\subsubsection{Infection Prevention and Control Practices}

This section of the checklist, relating to infection prevention and control (IPC) practices, includes items that investigate the knowledge of staff on hand hygiene with particular focus on the five hand hygiene moments identified by the World Health Organization, on the use of PPE for possible, probable, or confirmed COVID-19 cases and regarding the appropriate use of disinfectants. The moments with greater awareness of the usefulness of hand hygiene are before contact, after body fluid exposure risk and after PPE removal. Less attention is paid after contact with the patient and before a clean/aseptic maneuver. Only four facilities reported a preferred use of ABHR compared to washing hands with soap and water, although half of the facilities had made supplies of ABHR available and easily accessible in the care areas. Almost all the facilities' staff were aware of which PPE to use in assisting a possible, probable, or confirmed case of COVID-19, with greater concern given to the use of gloves (in 100\% of the facilities, it was reported as fundamental PPE). Monitoring of compliance in the practice of hand hygiene and regarding the correct use of PPE was carried out in only two facilities (14\%). As far as the disinfection of the rooms is concerned, all the residences use suitable disinfectants against SARS-CoV-2 but only four facilities $(29 \%)$ were aware of the need to apply the cleaning product for an adequate contact time.

\subsubsection{Communication}

The survey showed a good communication capacity of the structures during the emergency. The facilities demonstrate that they had followed the instructions provided by the local health authorities for reporting possible, probable, or confirmed cases of COVID19 , including serious respiratory infections that had resulted in hospitalization or death of the resident. Clusters of new onset respiratory symptoms among residents or health personnel (two or more cases in $48 \mathrm{~h}$ ) were frequently reported by the facilities (86\%).

In $93 \%$ of the sample analyzed, there was a procedure to inform residents, families, and facility staff members about suspected or confirmed cases of COVID-19. Finally, in nine out of 14 structures (64\%), the communication of a possible, probable, or confirmed COVID-19 case was envisaged before the transfer of a resident to a hospital, even for chronic treatments such as dialysis (Table 5 ).

A specific written plan for the COVID-19 emergency was identified in only four structures of the 14 interviewed. All the facilities reported a lack of information at the beginning of the health emergency with only five facility managers reporting having received information before the epidemic period (only in three cases had such information been received from the local health authority).

The analysis of the scores obtained by the facilities in every section of the checklist highlights a great variability between the scores for staff training, monitoring and screening; 
resident training, monitoring and screening; availability of PPE and other supplies; infection prevention and control practices. Conversely, visitor restrictions and communication areas show low variability in scores (Figure 2).

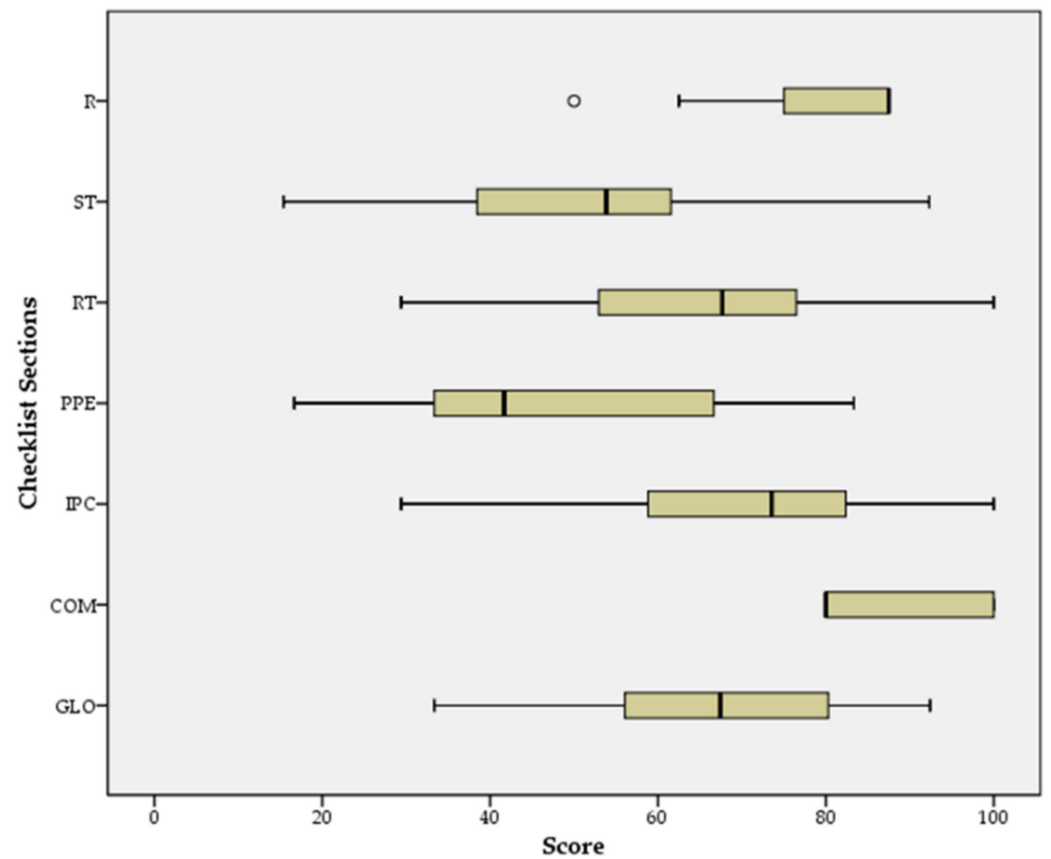

Figure 2. Distribution of facility scores by checklist section (R: restrictions policies for visitors and non-essential staff; ST: staff training, monitoring, and screening; RT: resident training, monitoring, and screening; PPE: Availability of PPE and other supplies; IPC: infection prevention and control (IPC) practices; COM: communication; GLO: global checklist score).

When the global checklist score distributions are compared according to the independent categorical variable "presence of SARS-CoV-2 cases during the emergency phase", the Mann-Whitney $\mathrm{U}$ test shows a statistically significant difference between the facility groups $(p<0.05)$ (Figure 3$)$.

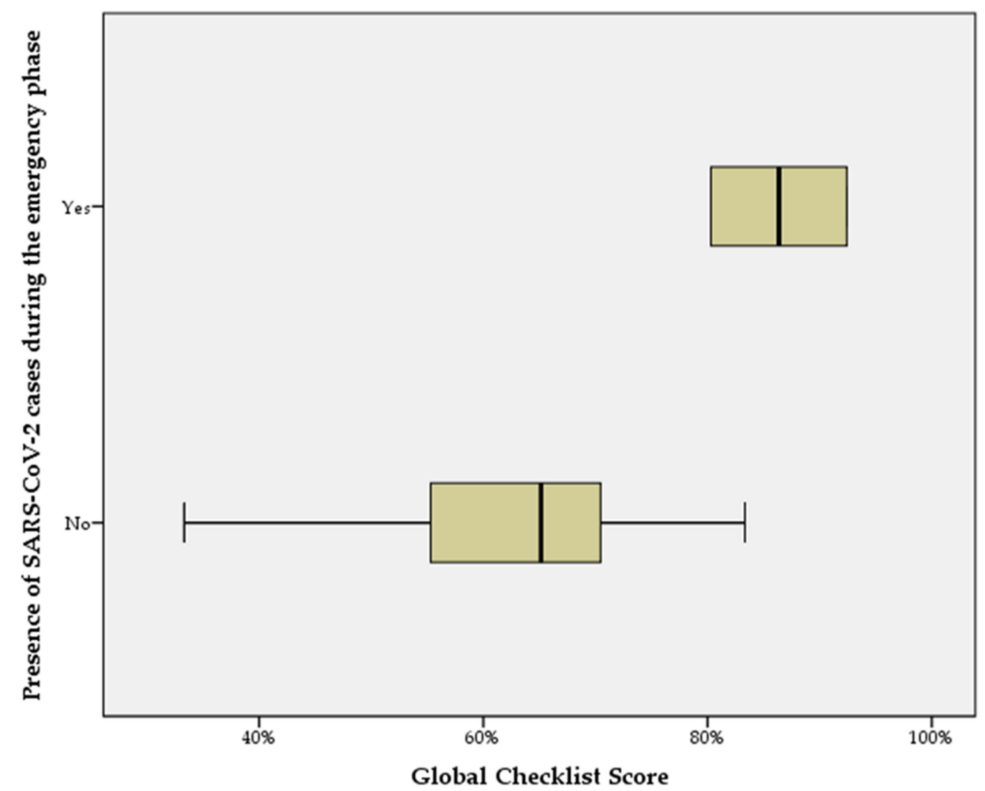

Figure 3. Distribution of total checklist scores obtained by facilities according to the presence of SARS-CoV-2 cases during the emergency phase. 


\subsection{Risk Perception Versus Facilities Hazard Analysis}

The three pairs of indicators that were built to compare risk perception versus actual hazards regarding IPC practices, quarantine/isolation and training areas, highlighted a potential incongruity between risk perception and actual hazard by the facilities.

A high perception (low outrage) was found for four facilities in the application of IPC practices (Figure 4, IPC practice plot, upper-left-side quadrant). However, this perception was not consistent with the subsequent field investigation, where an adequate application of IPC practices was not found. For the other facilities, perception was consistent with external evaluation.
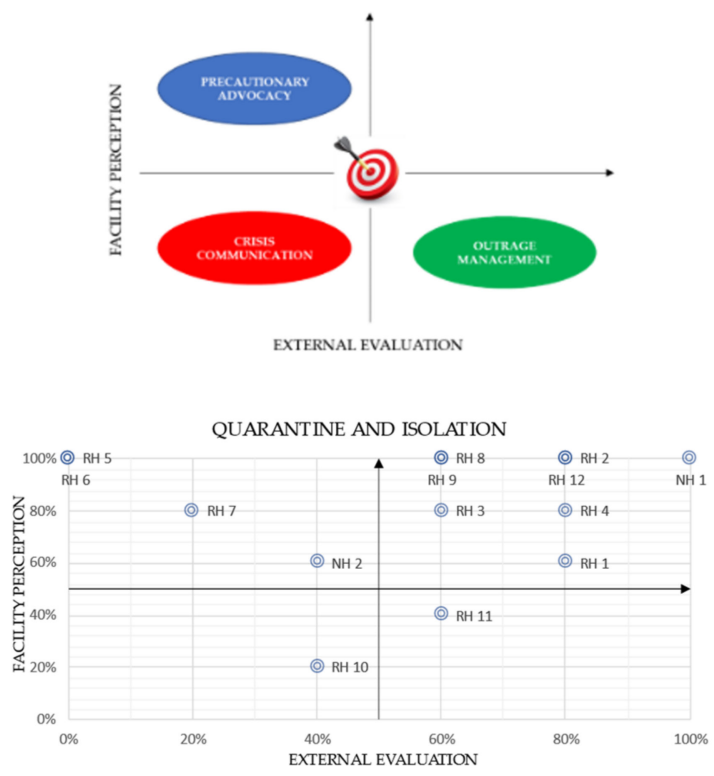
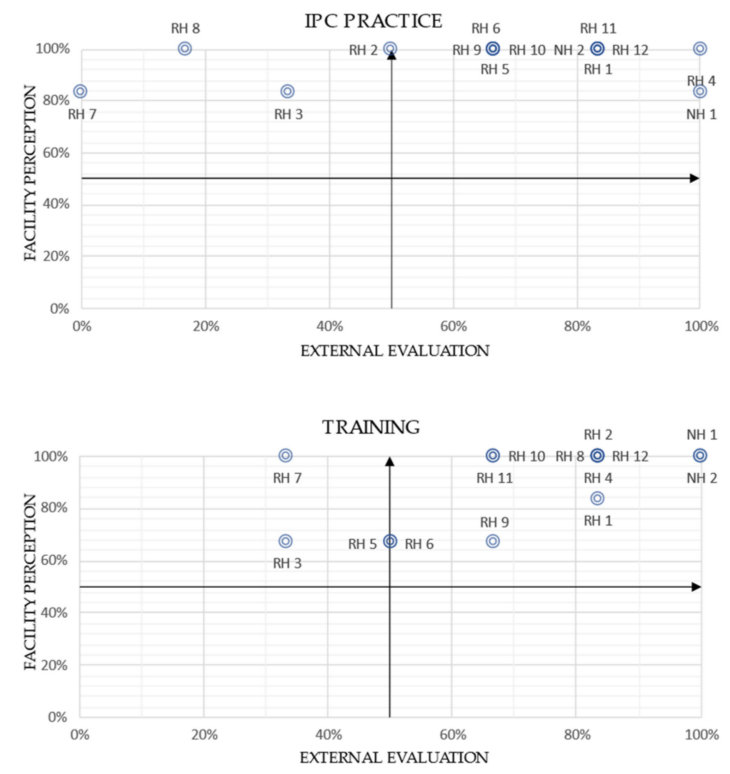

Figure 4. Perceptual map of risk (facility perception) versus hazard (external evaluation) for the IPC practice indicator, quarantine/isolation indicator and training indicator.

As regards quarantine/isolation indicators (Figure 4, quarantine and isolation plot), four facilities (upper-left-side quadrant) show a low risk perception not commensurate to the real hazard assessed by the external evaluation. One facility (RH10) showed a high outrage in these practices, which was proportionate with the level of danger assessed during the field investigation. Lastly, one facility (RH11), despite having an adequate isolation and quarantine competence, showed a high outrage on these items without having a high hazard.

In the area concerning healthcare staff training (Figure 4, training plot), the field investigation encountered a lack of training in at least two facilities (RH3-RH7), with extensive room for improvement by all retirement homes. On the other hand, most of the facilities reveal a high perception of the training activity carried out. Nursing homes showed a higher level of training and a commensurate perception of the same.

\section{Discussion}

Planning is a fundamental component of preparedness but does not consist solely of drawing up written plans. It is now widely recognized that preparedness must include a vulnerability assessment, skills evaluation, and training programs, and must strengthen the communication network. All these activities must be implemented in the planning phase. An adequate level of preparedness can be achieved only by providing all the tools necessary to develop an adequate response to the critical event [37].

In March 2020 in the city of Sassari, the Local Public Health Service of the Prevention Department issued a questionnaire to investigate the supply of personal protective equipment within the residential facilities. Nine of these facilities replied, reporting shortages of 
face masks (55.6\%), gowns (44.4\%), gloves, environmental sanitation products and products for disinfection and hand hygiene (22.2\%).

Beyond this snapshot assessment of available personal protective equipment and disinfectants, residential facilities were not routinely evaluated in infection prevention and control practices and in emergency response capacity, mainly because a dedicated monitoring system for these facilities is lacking.

An adequate level of staff and resident education, regular monitoring of care standards, improvements in hand and respiratory hygiene, the provision of adequate stocks of PPE devices and the promotion of social distancing are strong drivers to avoid an outbreak in a facility. Such measures should be supported by the ability to detect suspected cases of infection early and isolate them promptly and properly [38,39]. In our experience, it has been shown that the application of some measures was incomplete. Facilities complied to a greater extent with measures such as restrictions for visitors and timely communication of possible, probable, or confirmed COVID-19 cases. An explanation for such a high level of adherence is partly due to national regulations that imposed restrictions on visits and clear information on the need to immediately notify the residents' family doctor and the local health authorities of suspected or confirmed cases of infection [40,41].

The preventive lockdown of facilities, although effective, must be complemented by a set of other measures that limit the probability of SARS-CoV-2 infections within the structures. This probability is reduced as adherence to infection prevention and control practices increases. Nonetheless, there is no single procedure that can single-handedly lower the risk threshold to zero. A common finding was the failure to set up an adequate screening procedure before allowing access to the facilities, both for staff and, occasionally, for authorized visitors. This is partly due to a low perception of the real danger brought about by the sense of security given by the restrictions on visits from outsiders. When an entry screening is carried out, it is essentially based on measuring body temperature, but this assessment would be more effective if associated with an anamnestic interview seeking epidemiological information as well as other symptoms that can occur (e.g., sore throat, runny nose, anosmia, dysgeusia) [42].

Equally important is the daily symptom screening in residents, although this is made difficult by the frequent presence of other comorbidities, which makes early recognition of respiratory viral infections difficult, potentially delaying diagnosis and increasing the probability of viral spread [43]. Although a periodic testing strategy could provide greater guarantees (diagnosis of asymptomatic SARS-CoV-2 cases), daily symptom screening should not be neglected.

A risk analysis and management model that could effectively explain accident causation is the one predicted in Reason's Swiss cheese model, which has been applied several times to the hospital setting and that can be applied in our intervention setting [44]. The underlying assumptions of this model provide a system approach: a fallacy is more a consequence than the cause of the problem. Lapses and weaknesses in one defense do not allow a risk to materialize, since the presence of a single weak spot usually does not alone cause an outbreak, but if all the barriers have leak points (latent or active conditions), the ideal condition for the perfect storm may occur [45].

The prediction of latent conditions is therefore the foundation for ensuring a proper responsiveness of the system. For example, eight facilities have a specific procedure on new hospitalizations but just a few have provided for a quarantine period for the new resident, relying on the negative result of the diagnostic molecular test without ensuring a period of social distancing from the other inhabitants. Regardless of which of the two procedures is the most effective in reducing the transmission of infection, the perception of the effectiveness of the quarantine period and the diagnostic test usage are different within facilities without scientific evidence or on an assessment of the risk [46].

Moreover, a lack of specific training gives rise to an incongruity between perceived risk and actual hazard. This gap is also exacerbated by the failure of the facilities to provide written plans stating their practices and supported by scientific evidence. A 
specific plan, besides being essential for standardizing the daily practice of personnel working in the facility, is also a useful tool for educating new staff on the procedures to be adopted. The plan is not to be considered as a dogma, but rather, needs to be updated as new evidence is acquired. The lived experience of an epidemic outbreak seems to have significantly influenced the application of the procedures. Previous experience in dealing with a catastrophic event improves the ability of an organization to react to a new event [47]. This suggests that the public health authorities, who have the correct knowledge of the risk, should cooperate with the structures facing emergencies by increasing the capacity of the individual structures and assessing their specific characteristics (e.g., structural, managerial, organizational) [48]. In this regard, logistical-structural characteristics of the building are a fundamental element to allow adequate spaces for isolation and quarantine.

A clear knowledge of the responsiveness of each facility is a fundamental preparatory step for an adequate risk communication process and regarding the ability to put in place all procedures aimed at reducing the risk itself.

Management and coordination of healthcare professionals is essential to ensure an effective and timely response during an outbreak. Nurses and healthcare assistants are the largest group of health professionals in these facilities, and it is therefore essential that their training provides a good basic knowledge of IPC and health emergency management. The assessment of basic skills in disaster medicine is identified as a means capable of ensuring the application of the best health care practices during an emergency or a health crisis [49]. The core competencies comprise a broad set of indicators that describe all the skills needed by healthcare professionals to be able to confront the broad discipline of disaster medicine [50]. In particular, interventions implemented at the onset of an epidemic such as health monitoring and surveillance, epidemiological investigation, isolation and quarantine, fast and wide testing, protection of first responders and health workers and basic sanitation and hygiene, storage, distribution and dispensing of supplies are critical to damage control. This also requires basic knowledge of descriptive and analytical epidemiology, laboratory science, environmental and occupational health, infection control, effective communication practices, and social sciences.

The professionals involved should be able to support surveillance efforts and be familiar with the arrangements and procedures for reporting cases. Learning the basics of risk and health communication is crucial to informing affected individuals, their families and the media regarding exposure risks and potential preventive measures.

Finally, health professionals need to know the moral, ethical, and legal issues that are relevant to the management of affected populations and communities and the basic public health regulatory framework. Well-defined ethical principles must underlie decisionmaking processes in emergency situations (for example, decisions on the allocation or use of insufficient resources) [51].

Regarding the knowledge related to SARS-CoV-2 and IPC practices, we found that only six facilities had carried out specific training and, in most cases, this was attended by the facility staff on a voluntary basis.

Moreover, IPC measures were applied without a real understanding of the reasons that led to their application. Training on the causative agent responsible for the epidemic is essential as it enables staff to acquire new knowledge and deepen existing knowledge about the transmission paths, clinical manifestations, incubation times, virulence, infectivity, contagiousness, sources and reservoirs of infection. Knowledge of these characteristics allows the application of effective preventive measures (for example, an adequate isolation or use of PPE) and to promptly recognize suspicious cases to be sent for testing.

Nursing homes, providing accommodation to people with high clinical complexity, were inclined to provide adequate training to employees.

The training took place via e-learning and the main web platform used was provided by the National Institute of Heath. The main reasons for using this web platform were free usage, easy accessibility and advice from third parties. However, healthcare assistants expressed difficulties in the availability of this e-learning since access was restricted to nurses 
and medical doctors. The activity in the field made it possible to supply some knowledge but it is essential to organize an extensive training program capable of overcoming the shortcomings and weaknesses of healthcare professionals working in these sectors.

The field investigation was an effective method for clarifying how much more can be carried out to improve risk communication and evidence-based procedure in these facilities. One approach could be legislative, with a revision of the regional laws identifying people who are responsible for assessing preparedness in nursing homes and retirement homes. Providing a committee for healthcare-related infections such as that in hospitals or the provision of a medical director in residential facilities (currently present only in nursing homes) could significantly improve the safety of these facilities.

Effective communication between all stakeholders is vital for decision-making. Risk communication can be defined as the exchange of information and risk assessments between experts, legislative authorities, interest groups and citizens [52]. The objectives of this type of communication can be manifold: it can be used to reassure people or stimulate risk perception, to guide choices or motivate the population to apply precautions. A precondition of both types of communication is credibility. The "Crisis and Emergency Risk Communication" (CERC) model developed by the US CDC integrates the two approaches described above in a single multiphase communication model to be used in the context of health emergencies [53].

The CERC model can help health organizations to provide the public with information to make the best decisions and to accept the imperfect nature of choice by implementing six principles of effective emergency and risk communication:

- Be first: crises are time sensitive. Communicating information quickly is crucial. For citizens, the first source of information often becomes the preferred source.

- Be right: accuracy establishes credibility. Information can include what is known, what is not known, and what is being done to fill in the gaps.

- Be credible: honesty and truthfulness should not be compromised during crises.

- Express empathy: crises create harm, and the suffering should be acknowledged in words. Addressing what people are feeling, and the challenges they face, builds trust and rapport.

- Promote action: giving people meaningful things to do calms anxiety, helps restore order, and promotes some sense of control.

- Show respect: respectful communication is particularly important when people feel vulnerable. Respectful communication promotes cooperation.

The risk is having to fight, even before the pandemic, with infodemics or the viral spread of false, partial, or erroneous information [54]. Immediate and widespread sharing of information offered by digital and social media before it has been thoroughly verified can be dangerous (for example, the non-evidence-based use of drugs such as hydroxychloroquine) $[55,56]$.

This study involved a small sample of residential facilities for the elderly, although representative of one of the major cities in the Sardinian island, and a high response rate was achieved. A close deadline was given to complete the preliminary questionnaire and the field investigation was performed within a month, making it unlikely that facilities were influenced by the responses given by the other facilities.

The main limitation of this study consists in possible confounding factors due to the heterogeneous logistical-structural characteristics among the facilities, which may have played an important role in the genesis of SARS-CoV-2 outbreaks. It is also possible that the perceived risk observed was influenced by recent SARS-CoV-2 epidemics among the facilities, which may have expressed a perception of risk different from the usual one. Finally, this public health action would be difficult to manage on a large scale during an epidemic phase, especially due to the lack of human resources, indicating its use in a pre-epidemic period.

An unexpected element of our intervention was the willingness of the managers and facilities staff to open up to discussion on aspects not considered in the planning phase, 
in order to guarantee a better quality of care for their residents, and many expressed a readiness to collaborate in a subsequent training project.

The field investigation, using an interactive method of detection, made it possible to convey some information and advice regarding the management of infectious events to the facility staff and managers. The ICAR checklist made it possible to clearly identify the weaknesses in the facilities' defensive systems and can be used to recommend practices to be implemented.

In light of what has been observed and discussed, it seems appropriate to draw attention to the fact that in every crisis, leaders have two equally important responsibilities: solving the immediate problem and preventing it from happening again [57].

\section{Conclusions}

This study highlights how important it is for health authorities to acquire knowledge about risk perception among a population during an epidemic event, and compare it with the real hazard, so as to design a more effective public health response.

The method used for this investigation of nursing homes and retirement homes allowed a reliable and fast evaluation of the procedures implemented by the facilities.

To our best knowledge, this is the first field investigation that aims to assess the risk perception of COVID-19 outbreaks among retirement and nursing homes, comparing it with actual danger.

The new epidemic wave forces us to focus our attention on the present, but it is necessary to develop current plans by projecting ourselves into the future and promoting a new approach based on the prediction of critical events, providing the means to effectively address them. Avoiding this challenge is no longer an option. The ongoing pandemic, with its second and eventually third wave, will make it possible to evaluate in the near future the effectiveness of the interventions initiated in retirement and nursing homes who have joined the project, both in terms of the number of facilities affected by the penetration of the infection and in terms of cases that will be registered within them.

Supplementary Materials: The following are available online at https:/ /www.mdpi.com/article/10 .3390/ijerph18115712/s1, Table S1: Introductory questionnaire for the assessment of "Preparedness" in residential facilities for the elderly in the city of Sassari.

Author Contributions: Conceptualization, C.G. and D.G.; data curation, C.G., D.G. and M.D.; formal analysis, C.G. and D.G.; investigation, C.G., D.G., S.M., P.P.M. and S.B.; methodology, C.G., A.A. and P.C.; project administration, A.A. and P.C.; supervision, M.G.D., A.A. and P.C.; validation, M.D., M.A. and P.C.; writing—original draft, C.G. and D.G.; writing—review and editing, C.G., D.G., M.D. and P.C. All authors have read and agreed to the published version of the manuscript.

Funding: This research was supported by "Fondo di Ateneo per la Ricerca 2020", University of Sassari.

Institutional Review Board Statement: Not applicable.

Informed Consent Statement: Not applicable.

Data Availability Statement: The data presented in this study are available on reasonable request from the corresponding author.

Acknowledgments: The authors would like to thank Emma Dempsey for the English language revision.

Conflicts of Interest: The authors declare no conflict of interest.

\section{References}

1. Chen, J.; Lu, H.; Melino, G.; Boccia, S.; Piacentini, M.; Ricciardi, W.; Wang, Y.; Shi, Y.; Zhu, T. COVID-19 infection: The China and Italy perspectives. Cell Death Dis. 2020, 11, 1-17. [CrossRef]

2. European Centre for Disease Prevention and Control, Communicable Disease Threats Reports, Week 14, 29 March-4 April 2020. Available online: https:/ / www.ecdc.europa.eu/sites/default/files/documents/Communicable-disease-threats-report-4-apr2020.pdf (accessed on 28 February 2021). 
3. ISTAT, Impatto Dell'Epidemia COVID-19 Sulla Mortalità Totale Della Popolazione Residente Primo Trimestre 2020, 4 Maggio. 2020. Available online: https:/ / www.epicentro.iss.it/coronavirus/pdf/Rapporto_Istat_ISS.pdf (accessed on 28 February 2021).

4. $\quad$ European Centre for Disease Prevention and Control. Guide to Revision of National Pandemic Influenza Preparedness Plans-Lessons Learned from the 2009 A(H1N1) Pandemic; ECDC: Stockholm, Sweden, 2017; ISBN 978-92-9498-091-5. [CrossRef]

5. United Nations Office for the Coordination of Humanitarian Affairs. What is Preparedness? 2019. Available online: https: //www.humanitarianresponse.info/en/coordination/preparedness/what-preparedness (accessed on 28 February 2021).

6. World Health Organization. A Strategic Framework for Emergency Preparedness. 2017. Available online: http://apps.who.int/ iris/bitstream/10665/254883/1/9789241511827-eng.pdf (accessed on 7 February 2021).

7. WHO. Pandemic Influenza Risk Management: A WHO Guide to Inform E Harmonize National E International Pandemic Preparedness and Response; World Health Organization (WHO): Geneva, Switzerland, 2017. Available online: http://www.who.int/influenza/ preparedness/pandemic/influenza_risk_management_update2017/en/(accessed on 15 December 2020).

8. ECDC; WHO EURO. Guide to Revision of National Pandemic Influenza Preparedness Plans: Lessons Learned from the 2009 A(H1N1) Pandemic. European Centre for Disease Prevention and Control (ECDC) and World Health Organization Regional Office for Europe (WHO EURO). 2017. Available online: https://ecdc.europa.eu/sites/portal/files/documents/Guide-topandemic-preparedness-revised.pdf (accessed on 15 December 2020).

9. World Health Organization. Regional Office for the Western Pacific. Guidance on COVID-19 for the Care of Older People and People Living in Long-term Care Facilities, Other Non-acute Care Facilities and Home Care, Manila: WHO Regional Office for the Western Pacific. 2020. Available online: https:/ / apps.who.int/iris/handle/10665/331913 (accessed on 26 May 2021).

10. Ancidoni, A.; Bacigalupo, I. A National Survey on COVID-19 Infection in Long-stay Residential Care Homes (LSRCHs), The Italian National Institute of Health, 2020. Available online: https:/ / www.epicentro.iss.it/en/coronavirus/sars-cov-2-survey-rsa (accessed on 9 August 2020).

11. Logar, S. Care home facilities as new COVID-19 hotspots: Lombardy Region (Italy) case study. Arch. Gerontol. Geriatr. 2020, 89, 104087. [CrossRef] [PubMed]

12. Palombi, L.; Liotta, G.; Orlando, S.; Gialloreti, L.E.; Marazzi, M.C. Does the Coronavirus (COVID-19) Pandemic Call for a New Model of Older People Care? Front. Public Health 2020, 8, 311. [CrossRef] [PubMed]

13. Bianchetti, A.; Bellelli, G.; Guerini, F.; Marengoni, A.; Padovani, A.; Rozzini, R.; Trabucchi, M. Improving the care of older patients during the COVID-19 pandemic. Aging Clin. Exp. Res. 2020, 32, 1883-1888. [CrossRef] [PubMed]

14. Murgante, B.; Borruso, G.; Balletto, G.; Castiglia, P.; Dettori, M. Why Italy First? Health, Geographical and Planning Aspects of the COVID-19 Outbreak. Sustainability 2020, 12, 5064. [CrossRef]

15. Deiana, G.; Azara, A.; Dettori, M.; Delogu, F.; Vargiu, G.; Gessa, I.; Arghittu, A.; Tidore, M.; Steri, G.; Castiglia, P. Characteristics of SARS-CoV-2 positive cases beyond health-care professionals or social and health-care facilities. BMC Public Health 2021, 21, 83. [CrossRef]

16. European Centre for Disease Prevention and Control. Increase in Fatal Cases of COVID-19 among Long-Term Care Facility Residents in the EU/EEA and the UK. 19 November 2020. ECDC: Stockholm. 2020. Available online: https://www.ecdc.europa. $\mathrm{eu} / \mathrm{en} /$ publications-data/rapid-risk-assessment-increase-fatal-cases-covid-19-among-long-term-care-facility (accessed on 26 May 2021).

17. World Health Organization. Preventing and Managing COVID-19 across Long-term Care Services: Policy Brief, 24 July 2020. Available online: https:/ /apps.who.int/iris/handle/10665/333074 (accessed on 26 May 2021).

18. WHO. Expert Consultation on Outbreak Communications (2004: Singapore) \& World Health Organization. Communicable Diseases Cluster. 2005. Outbreak Communication: Best Practices for Communicating with the Public during an Outbreak: Report of the WHO Expert Consultation on Outbreak Communications held in Singapore, 21-23 September 2004. 2004. Available online: https:/ / apps.who.int/iris/handle/10665/69138 (accessed on 30 January 2020).

19. Rubin, G.J.; Amlôt, R.; Page, L.; Wessely, S. Public perceptions, anxiety, and behaviour change in relation to the swine flu outbreak: Cross sectional telephone survey. BMJ 2009, 339, b2651. [CrossRef]

20. Smith, R.D. Responding to global infectious disease outbreaks: Lessons from SARS on the role of risk perception, communication and management. Soc. Sci. Med. 2006, 63, 3113-3123. [CrossRef]

21. Tumpey, A.J.; Daigle, D.; Nowak, G. Communicating During an Outbreak or Public Health Investigation, CDC, Epidemic Intelligence Service. Available online: https:/ / www.cdc.gov/eis/field-epi-manual/chapters/Communicating-Investigation.html (accessed on 30 January 2020).

22. Coombs, W.T. Ongoing Crisis Communication: Planning, Managing, and Responding; SAGE Publications: Thousand Oaks, CA, USA, 2018.

23. Dettori, M.; Azara, A.; Loria, E.; Piana, A.; Masia, M.D.; Palmieri, A.; Cossu, A.; Castiglia, P. Population Distrust of Drinking Water Safety. Community Outrage Analysis, Prediction and Management. Int. J. Environ. Res. Public Health 2019, 16, 1004. [CrossRef]

24. Dettori, M.; Pittaluga, P.; Busonera, G.; Gugliotta, C.; Azara, A.; Piana, A.; Arghittu, A.; Castiglia, P. Environmental Risks Perception among Citizens Living Near Industrial Plants: A Cross-Sectional Study. Int. J. Environ. Res. Public Health 2020, 17, 4870. [CrossRef] 
25. Infanti, J.; Sixsmith, J.; Barry, M.M.; Núñez-Córdoba, J.; Oroviogoicoechea-Ortega, C.; Guillén-Grima, F. A Literature Review on Effective Risk Communication for the Prevention and Control of Communicable Diseases in Europe. Stockholm: ECDC. 2013. Available online: https://www.ecdc.europa.eu/sites/default/files/media/en/publications/Publications/risk-communicationliterary-review-jan-2013.pdf (accessed on 7 February 2021).

26. Dettori, M.; Arru, B.; Azara, A.; Piana, A.; Mariotti, G.; Camerada, M.V.; Stefanelli, P.; Rezza, G.; Castiglia, P. In the Digital Era, Is Community Outrage a Feasible Proxy Indicator of Emotional Epidemiology? The Case of Meningococcal Disease in Sardinia, Italy. Int. J. Environ. Res. Public Health 2018, 15, 1512. [CrossRef]

27. Riccardo, F.; Ajelli, M.; Andrianou, X.D.; Bella, A.; Del Manso, M.; Fabiani, M.; Bellino, S.; Boros, S.; Urdiales, A.M.; Marziano, V.; et al. Epidemiological characteristics of COVID-19 cases and estimates of the reproductive numbers 1 month into the epidemic, Italy, 28 January to 31 March 2020. Eurosurveillance 2020, 25, 2000790. [CrossRef]

28. Istituto Nazionale di Statistica (ISTAT); Istituto Superiore di Sanità (ISS). Impatto Dell'Epidemia COVID-19 Sulla Mortalità Totale Della Popolazione Residente, Primo Trimestre 2020, 4 May 2020. Available online: https://www.istat.it/it/files//2020/05 /Rapporto_Istat_ISS.pdf (accessed on 8 February 2021).

29. Bernardinelli, L.; Maida, A.; Marinoni, A.; Clayton, D.; Romano, G.; Montomoli, C.; Fadda, D.; Solinas, G.; Castiglia, P.; Cocco, P.L.; et al. Atlas of Cancer Mortality in Sardinia 1983-1987; Tipolito Olona: Copiano, Italy, 1994; pp. 13-17. ISBN 88-86405-01-4.

30. Chiang, C.W.K.; Marcus, J.H.; Sidore, C.; Biddanda, A.; Al-Asadi, H.; Zoledziewska, M.; Pitzalis, M.; Busonero, F.; Maschio, A.; Pistis, G.; et al. Genomic history of the Sardinian population. Nat. Genet. 2018, 50, 1426-1434. [CrossRef]

31. Deiana, G.; Azara, A.; Dettori, M.; Delogu, F.; Vargiu, G.; Gessa, I.; Stroscio, F.; Tidore, M.; Steri, G.; Castiglia, P. Deaths in SARS-Cov-2 Positive Patients in Italy: The Influence of Underlying Health Conditions on Lethality. Int. J. Environ. Res. Public Health 2020, 17, 4450. [CrossRef]

32. Istituto Nazionale di Statistica. Indicatori Demografici. Available online: http:/ / dati.istat.it/viewhtml.aspx?il=blank\&vh=0000 $\& v f=0 \& v c q=1100 \&$ graph=0\&view-metadata=1\&lang=it\&QueryId=18462\# (accessed on 20 September 2020).

33. Puci, M.V.; Loi, F.; Ferraro, O.E.; Cappai, S.; Rolesu, S.; Montomoli, C. COVID-19 Trend Estimation in the Elderly Italian Region of Sardinia. Front. Public Health 2020, 8, 153. [CrossRef]

34. Regione Autonoma della Sardegna. Coronavirus, Aggiornamento dei Dati in Sardegna (15 Marzo). 19 March 2020. Available online: http: / / www.regione.sardegna.it/j/v/2568? s=405478\&v=2\&c=289\&t=1 (accessed on 24 September 2020).

35. CDC. Infection Prevention and Control Assessment Tool for Nursing Homes Preparing for COVID-19. Version 1.0. 2020. Available online: https: / / www.cdc.gov / coronavirus / 2019-ncov/downloads/hcp/assessment-tool-nursing-homes.pdf (accessed on 30 January 2021).

36. Istituto Superiore di Sanità. Rapporto ISS COVID-19 n. 4/2020 Rev.-Indicazioni ad Interim per la Prevenzione e il Controllo Dell'Infezione da SARS-CoV-2 in Strutture Residenziali Sociosanitarie; Istituto Superiore di Sanità: Roma, Italy, 2020.

37. Staupe-Delgado, R.; Kruke, B.I. Preparedness: Unpacking and clarifying the concept. J. Conting. Crisis Manag. 2018, 26, 212-224. [CrossRef]

38. WHO. Infection Prevention and Control Guidance for Long-Term Care Facilities in the Context of COVID-19; WHO: Geneva, Switzerland, 2020; pp. 1-5.

39. Lai, C.-C.; Wang, J.-H.; Ko, W.-C.; Yen, M.-Y.; Lu, M.-C.; Lee, C.-M.; Hsueh, P.-R. COVID-19 in long-term care facilities: An upcoming threat that cannot be ignored. J. Microbiol. Immunol. Infect. 2020, 53, 444-446. [CrossRef]

40. DECRETO DEL PRESIDENTE DEL CONSIGLIO DEI MINISTRI 8 Marzo 2020. Ulteriori Disposizioni Attuative del Decreto-Legge 23 Febbraio 2020, n. 6, Recante Misure Urgenti in Materia di Contenimento e Gestione dell'Emergenza Epidemiologica da COVID-19. Available online: https:/ / www.gazzettaufficiale.it/eli/id/2020/03/08/20A01522/sg (accessed on 28 February 2021).

41. Assessorato Dell'igiene e Sanita' e Dell'assistenza Sociale-Regione Autonoma Della Sardegna. Determinazione n. 60 (Prot. N. 1790 del 29 January 2020). Preparazione e Risposta All'eventuale Emergenza Derivante da casi di Nuovo Coronavirus (2019 n-CoV) nel Territorio Regionale. Adozione Documento Operativo. Available online: http://www.regione.sardegna.it/documenti/1_42 2_20200409172056.pdf (accessed on 28 February 2021).

42. Jeong, T.H.; Pak, C.; Ock, M.; Lee, S.-H.; Son, J.S.; Jeon, Y.-J. Real Asymptomatic SARS-CoV-2 Infection Might be Rare: The Importance of Careful Interviews and Follow-up. J. Korean Med. Sci. 2020, 35, e333. [CrossRef]

43. Blain, H.; Rolland, Y.; Benetos, A.; Giacosa, N.; Albrand, M.; Miot, S.; Bousquet, J. Atypical clinical presentation of COVID-19 infection in residents of a long-term care facility. Eur. Geriatr. Med. 2020, 11, 1085-1088. [CrossRef]

44. Noh, J.Y.; Song, J.Y.; Yoon, J.G.; Seong, H.; Cheong, H.J.; Kim, W.J. Safe hospital preparedness in the era of COVID-19: The Swiss cheese model. Int. J. Infect. Dis. 2020, 98, 294-296. [CrossRef]

45. Reason, J. Human error: Models and management. BMJ 2000, 320, 768-770. [CrossRef]

46. Sethuraman, N.; Jeremiah, S.S.; Ryo, A. Interpreting Diagnostic Tests for SARS-CoV-2. JAMA J. Am. Med. Assoc. 2020, 323, 2249-2251. [CrossRef]

47. Seale, G.S. Emergency preparedness as a continuous improvement cycle: Perspectives from a postacute rehabilitation facility. Rehabil. Psychol. 2010, 55, 247-254. [CrossRef]

48. Pierce, J.R.; Morley, S.K.; West, T.A.; Pentecost, P.; Upton, L.A.; Banks, L. Improving Long-Term Care Facility Disaster Preparedness and Response: A Literature Review. Disaster Med. Public Health Prep. 2016, 11, 140-149. [CrossRef]

49. Adams, L.M.; Canclini, S.B.; Frable, P.J. Skip the infection, get the injection: A case study in emergency preparedness education. Nurse Educ. Pract. 2015, 15, 58-62. [CrossRef] 
50. Walsh, L.; Subbarao, I.; Gebbie, K.; Schor, K.W.; Lyznicki, J.; Strauss-Riggs, K.; Cooper, A.; Hsu, E.B.; King, R.V.; Mitas, J.A.; et al. Core Competencies for Disaster Medicine and Public Health. Disaster Med. Public Health Prep. 2012, 6, 44-52. [CrossRef]

51. James, J.J.; Benjamin, G.C.; Burkle, F.M.; Gebbie, K.M.; Kelen, G.; Subbarao, I. Disaster Medicine and Public Health Preparedness: A Discipline for All Health Professionals. Disaster Med. Public Health Prep. 2010, 4, 102-107. [CrossRef]

52. Leiss, W. Three Phases in the Evolution of Risk Communication Practice. Ann. Am. Acad. Political Soc. Sci. 1996, 545, 85-94. [CrossRef]

53. CDC. Crisis and Emergency Risk Communication (CERC) Manual. 2019. Available online: https://emergency.cdc.gov/cerc/ manual/index.asp (accessed on 15 December 2020).

54. Gallotti, R.; Valle, F.; Castaldo, N.; Sacco, P.; De Domenico, M. Assessing the risks of 'infodemics' in response to COVID-19 epidemics. Nat. Hum. Behav. 2020, 4, 1285-1293. [CrossRef]

55. Funnell, S.G.P.; Dowling, W.E.; Muñoz-Fontela, C.; Gsell, P.-S.; Ingber, D.E.; Hamilton, G.A.; Delang, L.; Rocha-Pereira, J.; Kaptein, S.; Dallmeier, K.H.; et al. Emerging preclinical evidence does not support broad use of hydroxychloroquine in COVID-19 patients. Nat. Commun. 2020, 11, 4253. [CrossRef]

56. Tuccori, M.; Convertino, I.; Ferraro, S.; Cappello, E.; Valdiserra, G.; Focosi, D.; Blandizzi, C. The Impact of the COVID-19 "Infodemic" on Drug-Utilization Behaviors: Implications for Pharmacovigilance. Drug Saf. 2020, 43, 699-709. [CrossRef] [PubMed]

57. Gates, B. Responding to Covid-19-A Once-in-a-Century Pandemic? N. Engl. J. Med. 2020, 382, 1677-1679. [CrossRef] [PubMed] 